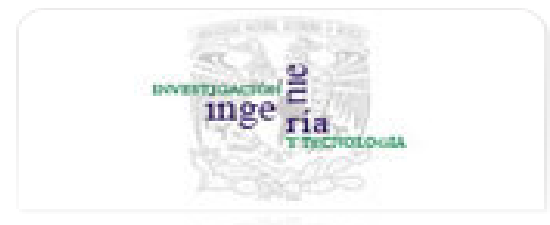

Ingeniería. Investigación y Tecnología

ISSN: $1405-7743$

iit.revista@gmail.com

Universidad Nacional Autónoma de México

México

Castillo Soria, F.R.; Pacheco Bautista, D.; Sánchez Meraz, M.

Frame, bit and chip error rate evaluation for a DSSS communication system

Ingeniería. Investigación y Tecnología, vol. IX, núm. 3, julio-septiembre, 2008, pp. 271-277

Universidad Nacional Autónoma de México

Distrito Federal, México

Available in: http://www.redalyc.org/articulo.oa?id=40490306

How to cite

Complete issue

More information about this article

Journal's homepage in redalyc.org

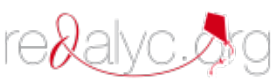

Scientific Information System Network of Scientific Journals from Latin America, the Caribbean, Spain and Portugal Non-profit academic project, developed under the open access initiative 
INGENIERÍA INVESTIGACIÓN Y TECNOLOGÍA IX. 3. 271-277, 2008

(ARTí́CULO ARDITRAdO)

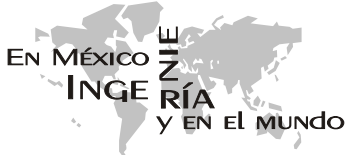

\title{
FRAME, DIT ANd CHIP ERROR RATE EVALUATION FOR A DSSS COMMUNICATION SYSTEM
}

\section{EVAluación de la tasa de ERRORES EN DIT, CHIP Y TRAMAS PARA UN SISTEMA dE COMUNICACINES DSSS}

\author{
F.R. Castillo-Soria ${ }^{1}$, D. Pacheco-Bautista ${ }^{1}$ y M. Sánchez-Meraz ${ }^{2}$ \\ ${ }^{1}$ Universidad del Istmo, Campus Ixtepec, Oaxaca, México y ${ }^{2}$ Departamento de Telecomunicaciones \\ SEPI-ESIME-IPN, Unidad Profesional "Adolfo López Mateos", México DF \\ E-mails: frcsoria@bianni.unistmo.edu.mx,mmeraz@ipn.mx
}

(Recibido: mayo de 2006; aceptado: junio de 2007)

\begin{abstract}
The relation between chips, bits and frames error rates in the Additive White Gaussian Noise (AWGN) channel for a Direct Sequence Spread Spectrum (DSSS) system, in Multiple Access Interference (MAl) conditions is evaluated. A simple error-correction code (ECC) for the Frame Error Rate (FER) evaluation is used. 64 bits (chips) Pseudo Noise $(P N)$ sequences are employed for the spread spectrum transmission.

An iterative Montecarlo (stochastic) simulation is used to evaluate how many errors on chips are introduced for channel effects and how they are related to the bit errors. It can be observed how the bit errors may eventually cause a frame error, i. e. CODEC or communication error. These results are useful for academics, engineers, or professionals alike.
\end{abstract}

Keywords: simulation, spread spectrum, multiple access, frame error rate.

\section{Resumen}

Se presenta la evaluación de la relación que tienen las tasas de chip, bits y tramas erróneas en un canal con Ruido Blanco Gaussiano Aditivo (RBGA) para un sistema de comunicaciones de espectro disperso de secuencia directa (DSSS) en Condiciones de Acceso Múltiple (CAM). La simulación emplea secuencias de Pseudo Ruido (PN) de 64 bits para la transmisión de espectro disperso.

Se utiliza una simulación de montecarlo (estocástica) para evaluar la cantidad de chips erróneos introducidos por los efectos del canal y cómo éstos se relacionan con los errores en bits. Se puede observar cómo los bits erróneos pueden causar eventualmente una trama errónea, es decir, un error en el CODEC o en la comunicación. Estos resultados pueden ser utilizados por académicos, ingenieros o profesionales del área.

Descriptores: simulación, espectro disperso, acceso múltiple, tasa de tramas erróneas.

\section{Introduction}

Simulation of communication systems has changed the way we design and implement communication systems.
Currently, there exists a great interest in modeling and simulation of communication systems. One can either evaluate a small part of the system, or evaluate general characteristics of different design situations in order to reduce the high cost of 
system testing and even decrease the human risks. However, the researcher should keep in mind that simulation results are reality approaches in the same way that the model would adequately describe the system in question. The bit error rate can be considered a fundamental part in design and implementation of communication systems.

DSSS systems have been widely accepted in the commercial world of mobile communications; nonetheless, simulating this kind of system requires high signal processes, it is in the best interest of the researcher to utilize the fastest processors at one's disposal, as well as the adequate software (Harada, et al., 2002). In this paper we present a software tool named SisCom, which can be used to evaluate Bit Error Rate (BER), Chip Error Rate (CER) and Frame Error Rate (FER) in DSSS Systems.

\section{System characteristics}

In the transmitter, information data frame is fed into a channel encoder, which is a linear block code $(10,6)$. The 10 bits codeword is then expanded for a spread spectrum code, as can be seen in figure 1. Next, the digital data is fed into a BPSK modulator.

Characteristics for codes in order to be used in CDMA are (Yang, 1998):
1. The cross-correlation should be zero or very small:

$$
R_{x y}(0)=x^{\top} y=\sum_{i=1}^{1} x_{i} y_{i}
$$

where $x$ and $y$ are two sequences or codes.

2. Each sequence in the set has an equal number of $1 \mathrm{~s}$ and $-1 \mathrm{~s}$, or the number of $1 \mathrm{~s}$ differs from the number of -1 s by at most 1 .

3. The scaled dot product of each code should be equal to 1 :

$$
\begin{aligned}
& R_{x x}(0)=x^{\top} x=\sum_{i=1}^{1} x_{i} x_{i} \\
& R_{x x}(0) / N=1
\end{aligned}
$$

The SisCom program has two types of code options for generating spread spectrum signals: Walsh codes and Pseudo Noise (PN) sequences. Walsh codes are generated using a 64 order Hadamard matrix (4), whose rows and columns are mutually orthogonal. The basic Hadamard matrix is (Lee, et al., 1998):

$$
H_{2}=\left[\begin{array}{ll}
0 & 0 \\
0 & 1
\end{array}\right]
$$

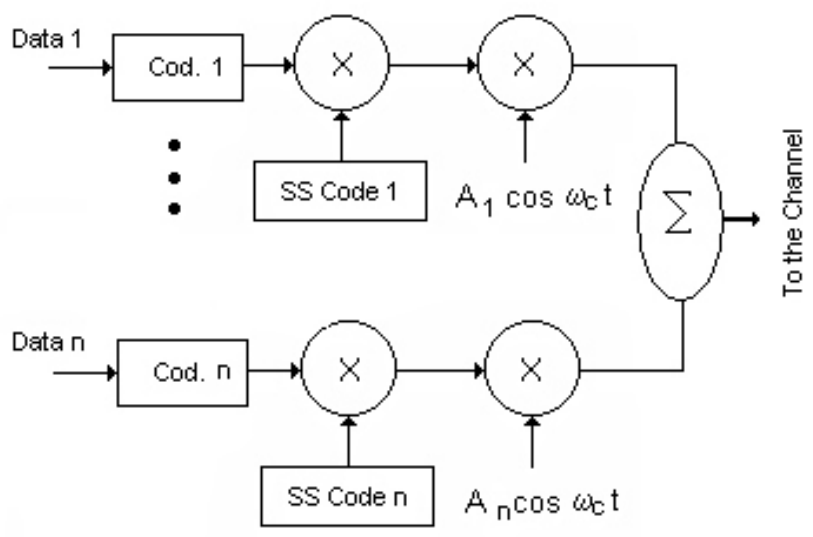

Figure 1. Transmitter 
One can find higher order matrices as follows:

$$
H_{2 N}=\left[\begin{array}{ll}
H_{N} & H_{N} \\
H_{N} & H_{N}
\end{array}\right]
$$

PN Sequences are generated with a MSRG (Modular Shift Register Generator) mechanization, known as Galois configuration. The sequence generation starts with the initial state vector: [ $\begin{array}{lllll}1 & 1 & 1 & 1\end{array}$ 11 ].

Figure 2 shows the MSRG mechanization used to generate PN sequences. Figure 3 shows the correlation function of PN sequences used (Lee et al., 1998; Harada et al., 2002).

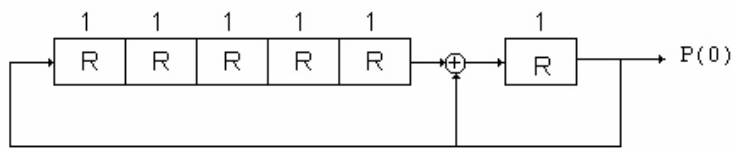

Figure 2. PN sequences generator

The output PN sequence is:

$\mathrm{PN}_{1}=[0,1,0,1,0,1,1,0,0,1,1,0,1,1,1,0,1,1,0$, $1,0,0,1,0,0,1,1,1,0,0,0,1,0,1,1,1,1,0,0,1,0,1,0$, $0,0,1,1,0,0,0,0,1,0,0,0,0,0,1,1,1,1,1,1]$. The other 62 vectors are delayed versions of the output sequence. Besides, this sequence has been added by an extra zero.
Continuous time analysis (for simplification) shows that the system wideband is mainly controlled by PN sequences as shown in (5), (6) and (7). The transmitter output signal $\chi(\mathrm{t})$ is (Stremler, 1998):

$$
\chi(t)=A c(t) p(t) \cos \omega_{c} t
$$

Where

$$
\begin{array}{ll}
\text { A : } & \text { Signal amplitude } \\
c(t): \text { Spread signal } \\
p(t): \text { Binary function representing the trans- } \\
\quad \text { mitted data } \\
\omega_{c}: \text { Carrier Frequency }
\end{array}
$$

The power spectral density $S_{c h}(\omega)$ of the spread signal $c(t)$ is:

$$
S_{c h}(\omega)=T_{c h} \sin c^{2}\left(\omega T_{c h} / 2\right)
$$

where

$$
T_{c h} \text { : Chip time }
$$

So that the power spectral density $S \Phi(\omega)$ of SSBPSK modulated signal can be described as:

$$
\begin{aligned}
& S_{\phi}(\omega)=\frac{1}{2} A^{2} T_{c h} \\
& \left\{\sin c^{2}\left[\left(\omega+\omega_{c}\right) T_{c h} / 2\right]+\sin c^{2}\left[\left(\omega-\omega_{c}\right) T_{c h} / 2\right]\right\}
\end{aligned}
$$

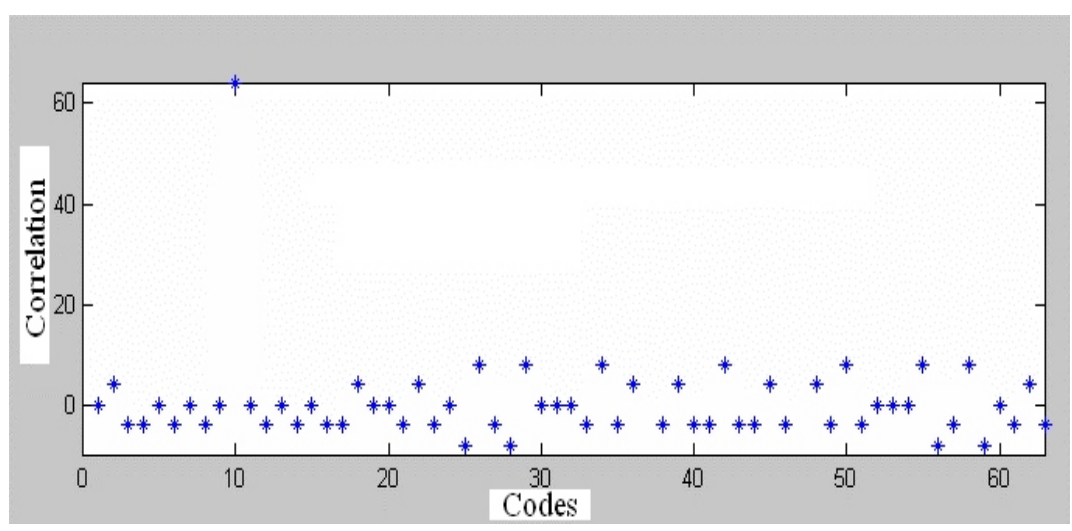

Figure 3. Correlation function for PN sequences whit inserted zero 
In the channel module of the SisCom program, the AWGN model and some other empirical and mathematical attenuation models are available; however, the most important quantity in this simulation is the Signal to Noise $(\mathrm{S} / \mathrm{N})$ ratio.

Figure 4 illustrates the correlation receiver used. In this block, chips, bits and frames are recovered. After one frame is recovered, the program goes back to the channel where noise and attenuation are added to the data signal in an iterative way.

As shown in figure 4, only one frame is recovered at the receiver, the other 19 frames are added only as interferers in the channel for this simulation.

\section{Simulation}

A very important characteristic of DSSS systems is the high noise tolerance. This simulation uses $\mathrm{S} / \mathrm{N}$ ratios from 0.02 to 0.04 into the channel; it means that the noise amplitude is over 30 times greater than the data amplitude. This characteristic is known as "spread spectrum jamming margin", which is directly proportional to the spread codes longitude. Even though the CER is high, the BER is maintained low. confidence. However, if more than one bit error occurs in one frame, we will have one error in the communication system. Therefore error randomness is a very important characteristic for a good CODEC performance. In this case, "block interleaving" may be included to offer better performance in the case of burst errors (Proakis, 2000).

Instead of using perfect orthogonal codes, we use PN sequences with a low correlation. Simulation shows how this non-perfect characteristic causes extra interference in the channel due to the fact that more users are connected. Synchronization facilities and easier electronic implementation justify the employment of PN sequences; the extra interference is in this case the downside of using them (Figure 5).

\section{Simulation characteristics:}

1) Frames: 10 bits (640 chips)

2) CODEC: linear block $(10,6)$

3) Multiple access: PN20-PN40 sequences

4) Modulation: BPSK

5) Channel: AWGN

6) Demodulator: correlator

7) Perfect synchrony Tx-Rx, is assumed

When the amount of channel noise causes a bit error, the channel CODEC can offer a bigger link

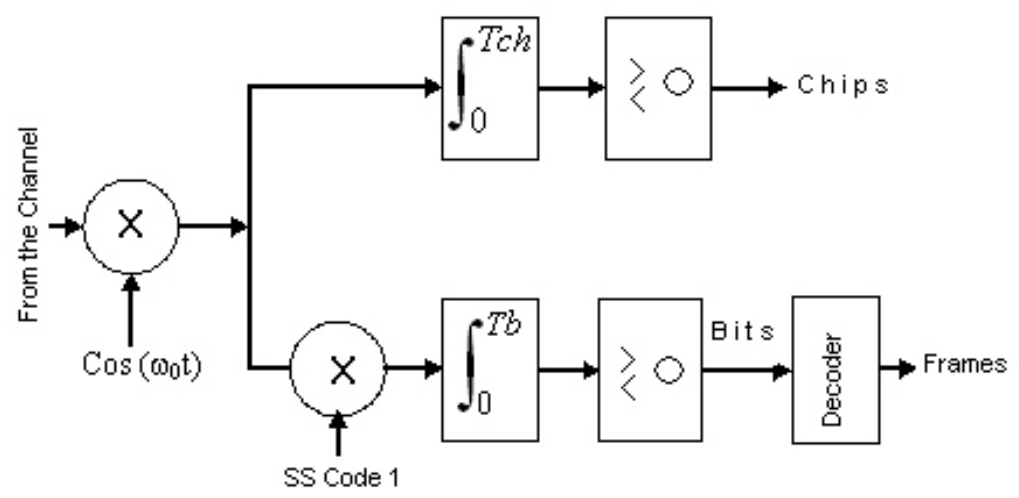

Figure 4. The receiver 


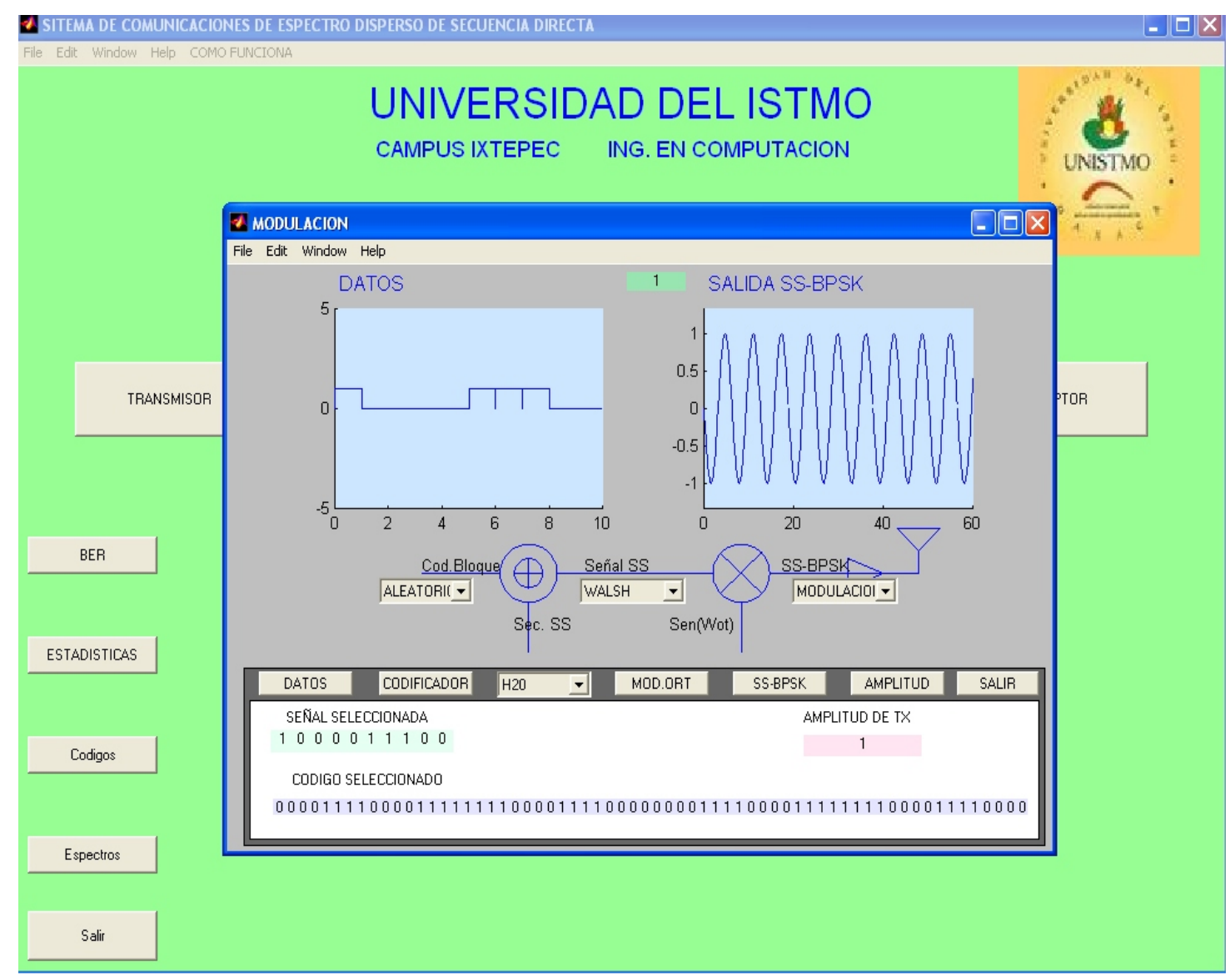

Figure 5. View of SisCom program

SisCom program was developed in MATLAB and requires from 30 minutes to 40 hours for one $10^{-4}$ error rate simulation running in a Pentium $4 \mathrm{CPU}$, $2.8 \mathrm{GHz}$ personal computer. This occurs because ten or more of the statistical events (errors) are needed in order to guarantee the results significance.

\section{Results}

Figure 6 illustrates the CODEC performance in multiple access conditions for 1,10 , and 20 users (blue, red, and black respectively). It is very difficult to compare these results to others. Because this software tool is unique, it is referenced only to underlying mathematics.
Figure 7 illustrates the FER (blue), BER (red) and CER (black) relations. FER is higher than BER for very low rates however, the convenience of using a CODEC is observed for high $\mathrm{S} / \mathrm{N}$ ratios, where the CODEC takes advantage of random errors on bits; at the same time the CER maintains very high error rates. 


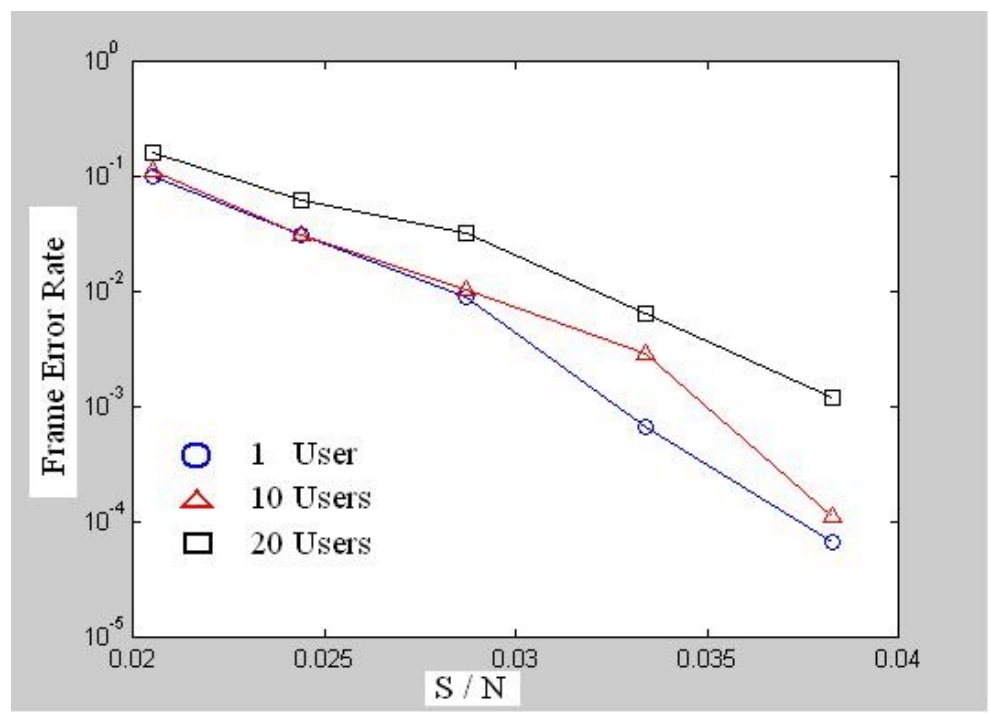

Figure 6. Frames error rate

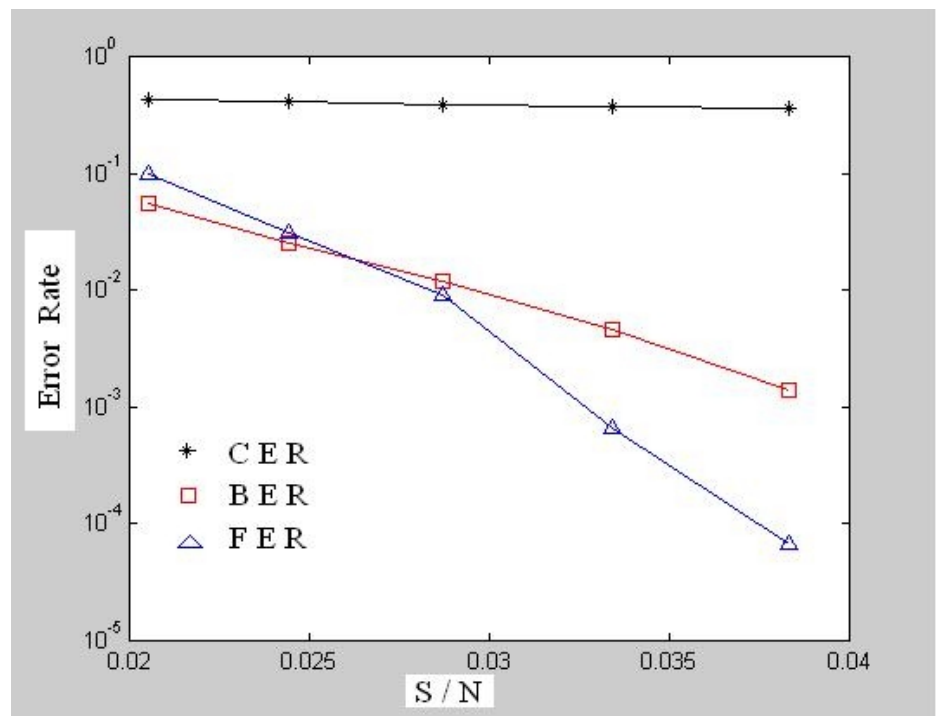

Figure 7. Chips, bits and frames error rates

\section{Conclusions}

We studied the behavior and the relation between chips, bits, and frames errors in the AWGN channel for a DSSS system in MAI conditions. It can be observed that low variations in CER, cause important variations in FER. Randomness of errors in the channel is the key for good CODEC performance.

\section{Acknowledgments}

We wish to thank the professors M.A. Arash Farzaneh and M.A. William Jurdan Davis III for their valuable contributions in revising the english version of this paper. 


\section{References}

Castillo-Soria F.R. Simulación del canal de comunicaciones del sistema de espectro disperso de secuencia directa. Master thesis, Research \& Graduate Section. Mexico DF. ESIME IPN. 2004.

Harada H. and Prasad R. Simulation and software radio for mobile communications. Boston, London. Artech House. 254 p. 2002.

Proakis J.G. Digital communications. Fourth edition. NY. McGraw Hill. 155 p. 2000.

Lee J.S. and Miller L.E. CDMA Systems engineering handbook. London. Artech House. 357 p. 1998.
Yang S.C. CDMA RF system engineering. London. Artech House. 214 p. 1998.

Nakamura S. Numerical analysis and graphic visualization with MATLAB. 2nd edition. Prentice Hall, 2001.

Moon T.K. Error correction coding, mathematical methods and algorithms. New Jersey, USA. Wiley \& Sons. 132 p. 2005.

Stremler F.G. Introducción a los sistemas de comunicación. Mexico. Spanish edition. Addison Wesley. 70 p. 1998.

\section{About the authors}

Francisco Ruben Castillo-Soria. Received his master of science in telecommunications engineering from IPN-ESIME, Research and Graduate Section in Mexico City, 2004. From 2001 to 2004 he was the telecommunications and computer science engineering major director of the Technological University of Baja California S.C. Campus La Paz in B.C.S. He has participated in Argentina, Mexico and also the Acapulco International Congress. Since 2005 he has been research-professor at the Universidad del Istmo, Oaxaca. His current research interests include simulation of telecommunications systems, protocols and multiple access for future generations of mobile communication systems.

Daniel Pacheco-Bautista. Received the master of science from the National Institute of Astrophysics, Optics and Electronics in Puebla, Mexico, 2003. Since 2004 he has been professor at Universidad del Istmo, Oaxaca, Mexico. He has presented his work in many national and international congresses. His current research includes wireless transceivers, frequency synthesizer, phase-locking and clock recovery for high-speed data communications and programming logic circuits.

Miguel Sánchez-Meraz. Received his master of science from the National Polytechnic Institute in Mexico. Since 1994 he has been research-professor at the Superior School of Mechanic and Electric Engineering, Research and Graduate section IPN. Professor Sanchez has been responsible for many academic and industrially-founded projects. His current research interests lie in simulation, digital signal processing based communications systems and security. 